\title{
NEOADJUVANT WEEKLY NAB-PACLITAXEL PLUS CARBOPLATIN FOLLOWED BY DOXORUBICIN PLUS CYCLOPHOSPHAMIDE WITH BEVACIZUMAB ADDED CONCURRENTLY TO CHEMOTHERAPY FOR OPERABLE TRIPLE-NEGATIVE INVASIVE BREAST CANCER
}

\author{
Jasgit C. Sachdev ${ }^{1}$, Jessica N. Snider ${ }^{2}$, Jeffrey W. Allen ${ }^{1}$, Lee S. Schwartzberg ${ }^{3}$, Robyn R. Young ${ }^{4}$, \\ Ahmed Y. Javed ${ }^{5}$, Matthew P. Smeltzer ${ }^{6}$, Furhan Yunus ${ }^{5}$, Carmel S. Verrier ${ }^{5}$, Mohammad Jahanzeb \\ ${ }^{1}$ Virginia G. Piper Cancer Center at Scottsdale Healthcare/TGen, Scottsdale, Arizona, USA, ${ }^{2}$ University of \\ Tennessee, Memphis, Tennessee, USA, ${ }^{3}$ The West Clinic, Memphis, Tennessee, USA, ${ }^{4}$ The Center for Cancer \\ and Blood Disorders, Fort Worth, Texas, USA, ${ }^{5}$ Baptist Cancer Center, Memphis, Tennessee, USA, ${ }^{6}$ University of \\ Memphis, Memphis, Tennessee, ${ }^{7}$ Sylvester Comprehensive Cancer Center, University of Miami, Deerfield Beach, \\ Florida, USA
}

Received: 27 April 2015 / Accepted: 17 May 2016

\begin{abstract}
Purpose: This phase II neoadjuvant study investigated whether nab-paclitaxel, carboplatin and bevacizumab given before neoadjuvant doxorubicin/cyclophosphamide (AC) produced higher pathologic complete response (pCR) rates in triplenegative breast cancer (TNBC) compared with historical results achieved with standard anthracycline/taxane regimens.

Patients and Methods: Eligible patients with operable TNBC $\geq 2 \mathrm{~cm}$ received four cycles of carboplatin (area under the curve 6 , day 1) plus nab-paclitaxel $\left(100 \mathrm{mg} / \mathrm{m}^{2}\right.$, days 1,8 and 15$)$ every 28 days, followed by four 14-day cycles of AC neoadjuvantly, with bevacizumab $10 \mathrm{mg} / \mathrm{kg}$ every 14 days for the first 6 cycles of neoadjuvant chemotherapy, resuming postoperatively to complete 1 year of antibody treatment. In-breast $\mathrm{pCR}$ and $\mathrm{pCR}$ (breast + nodes) were primary and secondary endpoints, respectively.

Results: Due to slow accrual, the study was closed after enrollment of 42 of 60 planned patients. Of the 38 patients who underwent surgery (efficacy population), 22 (58\%) achieved an in-breast pCR and $19(50 \%)$ achieved a pCR (breast + nodes). Neutropenia was the most common Grade 3/4 adverse event (57\% Grade 3 and 31\% Grade 4), but only 1 patient required hospitalisation and IV antibiotics for neutropenic fever. Other Grade $3 / 4$ events included anaemia (24\%), thrombocytopenia (29\%) and peripheral neuropathy (Grade 3, 5\%).

Conclusion: Our results demonstrate a substantially higher pCR rate, both in-breast and breast + nodes, with the combination of nab-paclitaxel plus carboplatin followed by AC, with concurrent bevacizumab, versus historic pCR rates with anthracycline-taxane regimens alone, supporting further investigation of this regimen, preferably in molecularly driven subsets, for the neoadjuvant treatment of patients with TNBC.
\end{abstract}

Key words: Bevacizumab, breast cancer, carboplatin, nab-paclitaxel, neoadjuvant, triple-negative

\section{Introduction}

Triple-negative breast cancer (TNBC) is generally more chemosensitive, with higher pathologic complete response (pCR) rates after neoadjuvant therapy compared with other subtypes of breast cancer. ${ }^{[1,2]}$ Patients with TNBC

Correspondence: Dr. Jasgit C. Sachdev, Virginia G. Piper Cancer Center Clinical Trials Scottsdale Healthcare, Scottsdale, Arizona, USA. Email: jasgit.sachdev@honorhealth.com who achieve a pCR have survival outcomes similar to the other breast cancer subtypes but a greater risk of relapse if residual disease remains. ${ }^{[2]} \mathrm{pCR}$ has been shown to correlate with improved disease-free survival (DFS) and overall survival (OS) in breast cancer. ${ }^{[3,4]}$ However, with standard anthracycline plus taxane regimens, only about $20-25 \%$ of hormone receptor-negative breast cancer patients achieve a pCR. ${ }^{[3,5]}$ Furtheroptimisation of neoadjuvant treatment for TNBC is needed. 
In patients with metastatic breast cancer (MBC), every 3-week nab-paclitaxel was superior to solvent-based paclitaxel. ${ }^{[6]}$ Basal-like breast cancers overexpress secreted protein acidic and rich in cysteine (SPARC). ${ }^{[7]}$ In pre-clinical models, SPARC transports albumin-bound (nab-) paclitaxel intracellularly, through SPARC-GP60-Caveolin 1 binding, that may contribute to antitumour efficacy. ${ }^{[8]}$ A higher frequency of BRCA-1 deficiency and other DNA damage repair defects in sporadic basal-like breast cancer may make these tumours more sensitive to platinum drugs. ${ }^{[9,10]}$ Carboplatin plus solvent-based paclitaxel was evaluated in first-line $\mathrm{MBC}$, with higher response rates (RRs) compared to single-agent paclitaxel. ${ }^{[11,12]}$ A phase I trial demonstrated the feasibility of combining nab-paclitaxel with carboplatin in solid tumours, including MBC. ${ }^{[13]}$ Angiogenesis also plays an integral role in the growth and progression of breast cancer. In the E2100 trial, bevacizumab added to weekly paclitaxel significantly improved RRs and median progression-free survival in HER2-negative MBC. ${ }^{[14]}$

Based on this efficacy data in the metastatic setting, we designed the current trial to evaluate whether integrating nab-paclitaxel, carboplatin and bevacizumab into an anthracycline-based neoadjuvant regimen would increase pCR rates with an acceptable safety and tolerability profile in patients with operable TNBC.

\section{Patients and Methods}

\section{Patient eligibility}

Eligible patients were women $\geq 18$ years of age with palpable ( $\geq 2 \mathrm{~cm}$ ) and operable, histologically confirmed, oestrogen receptor (ER) and progesterone receptornegative (per local testing, eligibility confirmed centrally by review of pathology reports), and negative for HER2 ( 0 or $1+$ on immunohistochemistry and/or documented non-amplification by fluorescence in situ hybridisation) invasive ductal carcinoma of the breast, with or without clinically positive nodes. Clinically positive nodes were identified by physical examination or imaging. Pathologic confirmation of clinically positive nodes such as with fine needle aspiration was not required but allowed. Eastern Cooperative Oncology Group (ECOG) performance status of $0-1$, baseline cardiac ejection fraction $(E F) \geq$ lower limit of normal (LLN) and adequate haematologic, renal and hepatic function were also required. Sentinel node biopsy before treatment was discouraged but not prohibited.
Major exclusion criteria included metastatic, T4, clinical $\mathrm{N} 2 \mathrm{~b}$ or N3 or inflammatory breast cancer; significant cardiac disease, uncontrolled hypertension, thrombotic or haemorrhagic events, coagulation disorders, another primary malignancy except treated basal or squamous cell carcinoma of the skin or in situ cervical cancer, unless disease-free for $\geq 5$ years. All patients provided written informed consent, and the study was approved by the institutional review board at each site.

\section{Study design and treatment}

This was a phase II, open-label, single arm nonrandomised study. All patients were required to undergo pre-treatment breast biopsies for correlative analyses. Whole blood and plasma samples were also collected at pre-specified time points. Patients received four 28-day cycles of intravenous nab-paclitaxel $\left(100 \mathrm{mg} / \mathrm{m}^{2}\right.$ on days 1,8 and 15 over $30 \mathrm{~min}$ ) plus carboplatin (area under the curve [AUC] 6 on day 1 over $30 \mathrm{~min}$ ), plus bevacizumab (10 mg/kg on days 1 and 15; over $90 \mathrm{~min}$ for cycle 1 , over 60 and $30 \mathrm{~min}$ for cycle 2 and beyond, respectively) [Figure 1].

This was followed by four 14-day cycles of intravenous doxorubicin/cyclophosphamide (AC) (doxorubicin [60 $\mathrm{mg} / \mathrm{m}^{2}$ on day 1 over $15 \mathrm{~min}$ ], cyclophosphamide [600 $\mathrm{mg} / \mathrm{m}^{2}$ on day 1 over $\left.30 \mathrm{~min}\right]$ ) and bevacizumab ( $10 \mathrm{mg} / \mathrm{kg}$ on day 1 for the first 2 cycles only). Surgery, including axillary staging, was performed between 2 and 6 weeks after the last dose of AC. Postoperatively, patients received eight 28 -day cycles of bevacizumab $(10 \mathrm{mg} / \mathrm{kg}$ on days 1 and 15) after a minimum of 4 weeks from surgery and evidence of complete wound healing.

During pre-operative cycles 5-8, prophylactic granulocyte colony-stimulating factor (G-CSF) was required. During cycles 1-4, G-CSF was not to be used as primary prophylaxis but was allowed for febrile neutropenia and as secondary prophylaxis for subsequent cycles.

Dose modification criteria for haematologic and nonhaematologic toxicities are described in Supplementary Appendix 1. Mid-study, in compliance with the FDA guidance issued around changes in creatinine methodology and carboplatin dosing, a glomerular filtration rate cap of $125 \mathrm{~mL} / \mathrm{min}$ was implemented for the Calvert formula so 


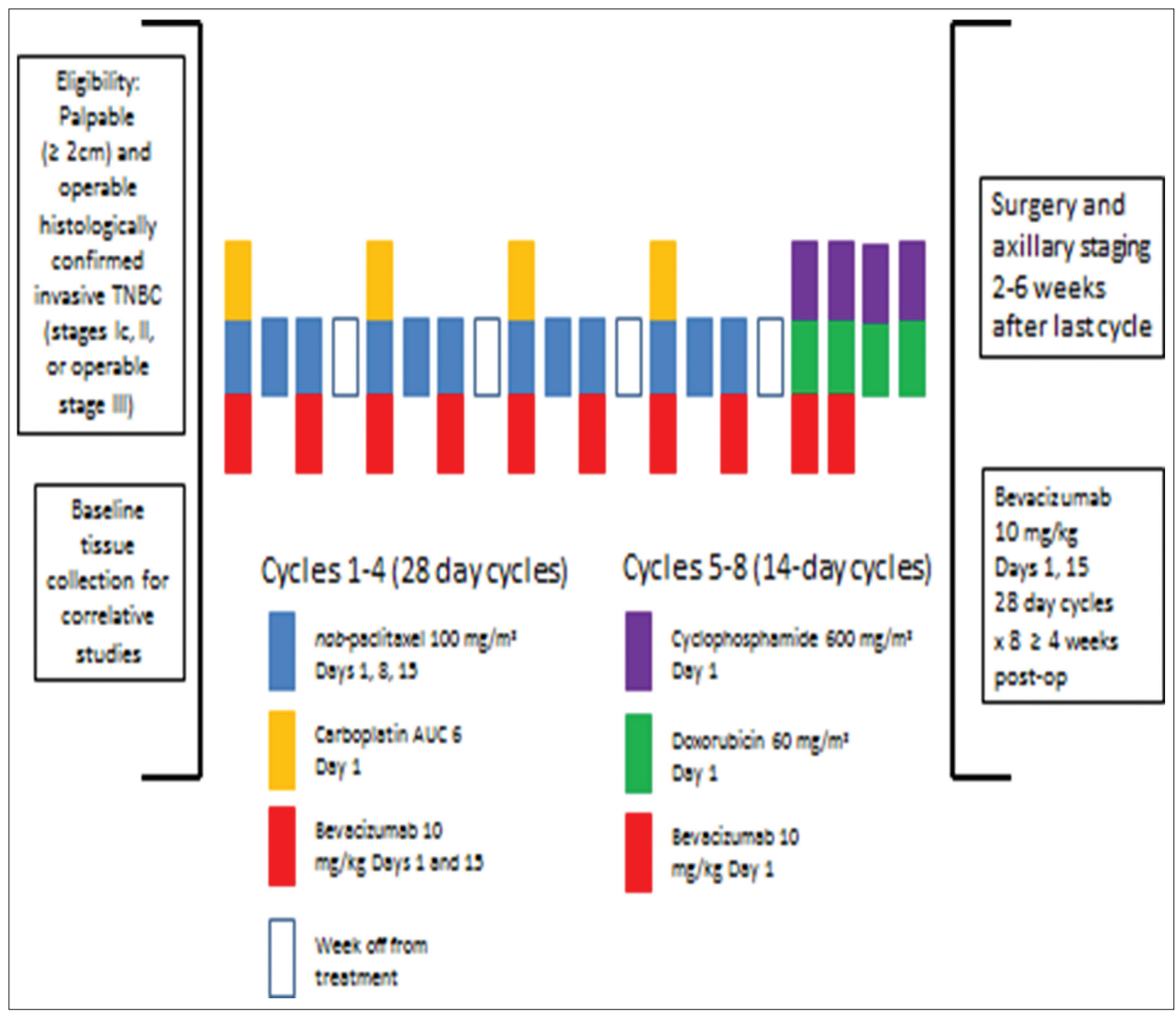

Figure 1: Treatment schema

that the maximum dose of carboplatin for any patient was not to exceed $900 \mathrm{mg} .{ }^{[15]}$

No dose reductions of bevacizumab were allowed, and treatment was held if the chemotherapy component was delayed. Protocol-specified therapy was discontinued for progressive disease, unacceptable toxicity, withdrawal of consent or physician judgment.

\section{Efficacy and safety assessments}

The primary endpoint of the study was the in-breast $\mathrm{pCR}$ rate after 8 cycles of pre-operative therapy, defined as no histologic evidence of invasive tumour cells (with or without carcinoma in situ) in the surgical breast specimen. Secondary objectives included near-pCR rate $(\leq 0.5 \mathrm{~cm}$ of residual invasive tumour in the breast) and $\mathrm{pCR}$ breast + nodes (no invasive tumour cells in the breast, axillary and sentinel nodes). Clinical response was assessed by physical examination, with clinical complete response (cCR), clinical partial response (cPR) and stable disease
(SD) defined by Response Evaluation Criteria in Solid Tumours version 1.0 (Supplementary Appendix 2). Rate of breast-conserving surgery, safety and tolerability were also assessed, including cardiac safety with echocardiogram or multigated acquisition (MUGA) scans required on all patients at pre-specified time points. Toxicities were graded using the NCI common terminology criteria of adverse events (AEs) version 3.0.

\section{Statistical considerations}

A 60 patient sample size, assuming a 10\% attrition rate, was calculated based on an estimated pCR rate of $25 \%$ with a standard taxane plus anthracycline regimen in ERnegative and HER2-negative tumours in earlier studies. A sample size of 57 patients would be required to show an increase in pCR rate to $40 \%$, to test this one-sided hypothesis with approximately $80 \%$ power and a type I error rate (alpha) $\leq 0.05$. The efficacy population was defined as all patients who underwent definitive breast surgery and was used for the efficacy analyses of cRR and 
Table 1: Baseline patient demographics and clinical characteristics

\begin{tabular}{|c|c|c|}
\hline \multirow{2}{*}{$\begin{array}{l}\text { Demographics } \\
\text { Age, years }\end{array}$} & \multicolumn{2}{|c|}{ Patients treated $n=42(\%)$} \\
\hline & & \\
\hline Median & 52 & \\
\hline Range & $35-69$ & \\
\hline \multicolumn{3}{|l|}{ Race } \\
\hline African-American & 21 & 50 \\
\hline Caucasian & 20 & 48 \\
\hline Other & 1 & 2 \\
\hline \multicolumn{3}{|l|}{ Menopausal status } \\
\hline Premenopausal & 13 & 31 \\
\hline Perimenopausal & 3 & 7 \\
\hline Postmenoapusal & 26 & 62 \\
\hline \multicolumn{3}{|c|}{ Clinical staging at baseline } \\
\hline cT1 & 4 & 10 \\
\hline сT2 & 24 & 57 \\
\hline cT3 & 14 & 33 \\
\hline cNO & 19 & 45 \\
\hline $\mathrm{cN} 1$ & 19 & 45 \\
\hline cN2a & 4 & 10 \\
\hline \multicolumn{3}{|l|}{ Tumour grade } \\
\hline 1 & 1 & 2 \\
\hline 2 & 8 & 19 \\
\hline 3 & 30 & 72 \\
\hline Not reported & 3 & 7 \\
\hline
\end{tabular}

pCR. The evaluable population was defined as all patients who received at least $75 \%$ of the total protocol defined pre-operative treatment cycles and for whom pathological response data were available. The safety population included all patients who received at least 1 dose of study treatment. Statistical analyses were descriptive.

\section{Results}

\section{Patient characteristics}

Forty-two of 60 planned patients were enrolled between January 2009 and January 2013 and received treatment on the study. At the prevailing accrual rate, it would have required an additional 12-18 months to enroll the remaining evaluable patients provided no other competing studies were to open during the same time period, so accrual was closed at that point. Baseline characteristics are described in Table 1.38 patients proceeded to surgery and constitute the efficacy population, 4 patients came off the study before surgery ( 2 for patient decision, 1 for disease progression and 1 for atypical chest pain); 36 patients received $\geq 75 \%$ of the required pre-operative therapy ( $\geq 6$ cycles) and comprise the evaluable population. The post-operative portion of the study is still ongoing, and the present analysis is restricted to the reporting of the primary endpoint of $\mathrm{pCR}$ after pre-operative treatment.

\section{Treatment delivery}

Among the 38 patients who constitute the efficacy population, 29 patients $(76 \%)$ missed at least one dose of nab-paclitaxel of a total of 12 planned doses over 4 cycles. The median dose intensity/week of nab-paclitaxel averaged over 4 cycles was $68.75 \mathrm{mg} / \mathrm{m}^{2}\left(37.5-75 \mathrm{mg} / \mathrm{m}^{2}\right)$, which was $92 \%$ of the planned dose intensity/week/ cycle $(75 \mathrm{mg} / \mathrm{m}+)$. The median dose intensity delivered for the other agents was $100 \%$ of planned. Two patients required a dose reduction of nab-paclitaxel to dose level-1 $\left(80 \mathrm{mg} / \mathrm{m}^{2}\right)$, and four patients required reduction of carboplatin to dose level-1 (AUC 5) for haematologic toxicity. Two patients did not complete at least $75 \%$ of the planned cycles before proceeding to surgery due to haematologic toxicities.

\section{Treatment response}

In the efficacy population, an in-breast pCR (primary endpoint) was observed in 22 patients $(58 \% ; 95 \%$ confided interval [CI]: $41-74 \%) ; 19$ patients $(50 \%$; 95\% CI: 33-67\%) experienced pCR in both breast and nodes. An additional three patients (8\%) experienced a near-pCR inthe breast, while residual tumour $>0.5 \mathrm{~cm}$ was found in 13 patients (34\%). Similar results were observed in the evaluable population [Table 2]. Of the 23 patients who were clinically node positive at baseline, 20 were evaluable for the $\mathrm{pCR}$ endpoint. Twelve of these 20 patients $(60 \%)$ achieved a pN0 status (pathologically negative nodes) at surgery. An additional three patients had micrometastatic disease in the nodes (pN1mi).

A cCR was observed in 29 of 38 patients (76\%) in the efficacy population, $5(13 \%)$ achieved a cPR and $3(8 \%)$ had SD [Table 2]. RRs were similar in the evaluable population. 
Table 2: Patient RRs and surgical outcomes

\begin{tabular}{|c|c|c|}
\hline Response category & $\begin{array}{c}\text { Efficacy population } \\
n=38(\%)\end{array}$ & $\begin{array}{c}\text { Evaluable population } \\
\qquad n=36(\%)\end{array}$ \\
\hline \multicolumn{3}{|l|}{ Pathologic response } \\
\hline In-breast pCR & $22(58)$ & $21(58)$ \\
\hline pCR breast+nodes & $19(50)$ & $18(50)$ \\
\hline pCR (breast only) & $3(8)$ & $3(8)$ \\
\hline Near-pCR breast (Residual tumour $\leq 0.5 \mathrm{~cm}$ in breast) & $3(8)$ & $2(6)$ \\
\hline Residual disease (tumour $>0.5 \mathrm{~cm}$ in breast) & $13(34)$ & $13(36)$ \\
\hline \multicolumn{3}{|l|}{ Best clinical response } \\
\hline $\mathrm{CR}$ & $29(76)$ & $28(78)$ \\
\hline PR & $5(13)$ & $4(11)$ \\
\hline SD & $3(8)$ & $3(8)$ \\
\hline Missing $^{\mathrm{a}}$ & $1(3)$ & $1(3)$ \\
\hline \multicolumn{3}{|l|}{ Surgical outcome } \\
\hline Breast-conserving surgery & $20(53)$ & $19(53)$ \\
\hline Mastectomy & $18(47)$ & $17(47)$ \\
\hline
\end{tabular}

${ }^{a}$ Clinical response could not be verified, RRs: Response rates. PCR: Pathologic complete response, CR: Complete response, PR: Partial response, SD: Stable disease

\section{Toxicity}

The majority of AEs were Grade 1/2 (57\% Grade 1, $29 \%$ Grade 2, 12\% Grade 3 and 2\% Grade 4). Ten of 42 patients (24\%) experienced at least 1 serious adverse event (SAE) related to study treatment, with a total of 23 SAEs [Supplemental Table 1].

The most frequent AEs (all grades) were anaemia (81\%), neutropenia $(81 \%)$, nausea $(76 \%)$, fatigue $(71 \%)$ and thrombocytopenia $(60 \%)$ [Table 3]. The most frequent Grade 3/4 AEs were neutropenia (57\% Grade 3 and 31\% Grade 4), thrombocytopenia (29\% Grade 3) and anaemia (21\% Grade 3 and 2\% Grade 4). Despite the high rate of neutropenia, only one patient developed neutropenic fever requiring IV antibiotics. Peripheral neuropathy was reported in $31 \%$ of patients (5\% Grade 3 ). Grade $1 / 2$ hypertension and proteinuria occurred in $36 \%$ and $10 \%$ of patients, respectively, and there were no reported Grade 3/4 events.

Cardiac function was assessed at baseline and before surgery. Of the 42 patients, paired echocardiograms or MUGA scans were available for 37. The median EF at baseline was $62.4 \%$ (range 53.0-80.0), compared with $60.2 \%$ (range $48.7-70.7$ ) at the completion of pre- operative treatment. Six patients experienced a drop in $\mathrm{EF} \geq 10 \%$ but not to below the institutional LLN. There were no cases of clinical congestive heart failure reported.

\section{Discussion}

To our knowledge, this is the first report of a combination of weekly nab-paclitaxel plus carboplatin followed by AC with concurrent bevacizumab in the neoadjuvant treatment of TNBC. In this study, we observed a $58 \%$ in-breast pCR rate and $50 \%$ of patients achieved a pCR in both breast and nodes.

To put our results in context, we examined recently presented data from two randomised phase II trials evaluating similar neoadjuvant regimens for early-stage breast cancer. [Table 4] In the GeparSixto trial, a significant increase in the pCR rate (breast plus nodes), from $36.9 \%$ to $53.2 \%(\mathrm{p}=0.005)$, was observed with the addition of carboplatin for patients with TNBC. All patients received bevacizumab. ${ }^{[16]}$ Similarly, the Cancer and Leukaemia Group (CALGB) 40603 trial in a $2 \times 2$ randomised design reported an absolute difference of $14 \%$ in breast $\mathrm{pCR}$ rate with carboplatin versus no carboplatin (60\% vs. $46 \%$, $P=0.0018)$, and $11 \%$ (59\% vs. $48 \%, P=0.0089)$ with bevacizumab versus no bevacizumab. ${ }^{[17]}$ No significant 
Table 3: AEs occurring in $>5 \%$ of patients $(n=42)$

\begin{tabular}{|c|c|c|c|}
\hline Adverse Event & Any grade $n(\%)$ & Grade $3 n$ (\%) & Grade $4 n(\%)$ \\
\hline \multicolumn{4}{|l|}{ Haematologic } \\
\hline Anaemia & $34(81)$ & $9(21)$ & $1(2)$ \\
\hline Neutropenia & $34(81)$ & $24(57)$ & $13(31)$ \\
\hline Thrombocytopenia & $25(60)$ & $12(29)$ & 0 \\
\hline \multicolumn{4}{|l|}{ Non-haematologic } \\
\hline Nausea & $32(76)$ & $2(5)$ & 0 \\
\hline Fatigue & $30(71)$ & $2(5)$ & 0 \\
\hline Mucositis & $21(50)$ & $2(5)$ & 0 \\
\hline Alopecia & $16(38)$ & $1(2)$ & 0 \\
\hline Epistaxis & $16(38)$ & 0 & 0 \\
\hline Anorexia & $15(36)$ & $1(2)$ & 0 \\
\hline Hypertension & $15(36)$ & 0 & 0 \\
\hline Peripheral neuropathy & $13(31)$ & $2(5 \%)$ & 0 \\
\hline Diarrhoea & $10(24)$ & 0 & 0 \\
\hline Vomiting & $10(24)$ & $2(5)$ & 0 \\
\hline Taste alteration & $9(21)$ & 0 & 0 \\
\hline Dyspnoea & $8(19)$ & 0 & 0 \\
\hline Constipation & $7(17)$ & 0 & 0 \\
\hline Headache & $7(17)$ & $1(2)$ & 0 \\
\hline LFT elevation & $7(17)$ & 0 & 0 \\
\hline Pain & $7(17)$ & 0 & 0 \\
\hline Bone pain & $6(14)$ & $1(2)$ & 0 \\
\hline Urinary tract infection & $5(12)$ & $1(2)$ & 0 \\
\hline Dyspepsia & $4(10)$ & 0 & 0 \\
\hline Proteinuria & $4(10)$ & 0 & 0 \\
\hline Cough & $3(7)$ & 0 & 0 \\
\hline Dehydration & $3(7)$ & $1(2)$ & 0 \\
\hline Flu-like syndrome & $3(7)$ & 0 & 0 \\
\hline GERD & $3(7)$ & 0 & 0 \\
\hline Hot flashes & $3(7)$ & $1(2)$ & 0 \\
\hline Hypokalaemia & $3(7)$ & 0 & 0 \\
\hline
\end{tabular}

AEs: Adverse events

treatment interaction was found between carboplatin and bevacizumab $(P=0.52)$. Intrinsic subtyping based on PAM50 showed an association between higher pCR rates in the basal subtype of TNBC for bevacizumab, but a similar predictive value was not demonstrated for carboplatin. No definite mRNA gene expression signatures predictive for carboplatin benefit were revealed. ${ }^{[18]}$

The lack of a control arm in our study, the presence of bevacizumab in both arms in the GeparSixto trial, and the lack of power to compare the carboplatin arm alone to the control arm without carboplatin or bevacizumab in the CALGB 40603 trial make it difficult to definitively conclude the contribution of carboplatin to $\mathrm{pCR}$ rates. However, these trials including our study provide a consistent signal of similar significant increases in $\mathrm{pCR}$ rates with carboplatin added to a taxane plus anthracycline backbone in TNBC. In addition, in the ISPY-2 trial, the combination of carboplatin plus veliparib plus standard neoadjuvant chemotherapy predicted for a pCR rate of $52 \%$ in the hormone receptor-negative/HER2-negative subgroup compared with $26 \%$ in the control group based 
Table 4: Summary of recent randomised neoadjuvant trials investigating carboplatin and/or bevacizumab in TNBC $[16,17,21,22]$

\begin{tabular}{|c|c|c|c|c|}
\hline Study & References & $\begin{array}{l}\text { Study } \\
\text { population (N) }\end{array}$ & Design & Efficacy \\
\hline GeparQuinto & $\begin{array}{l}\text { Von } \\
\text { Minckwitz } \\
\text { et al. (2012) }\end{array}$ & $\begin{array}{l}\text { HR-negative } \\
\text { breast can- } \\
\text { cer (N-1948; } 663 \\
\text { TNBC) }\end{array}$ & $\begin{array}{l}\text { EC } \rightarrow \text { Docetaxel } \pm \text { Bevacizum- } \\
a b\end{array}$ & $\begin{array}{l}\text { pCR (breast+nodes): } 18.4 \% \text { (with beva- } \\
\text { cizumab) versus } 14.9 \% \text { (no bevacizumab) } \\
\text { ( } P=0.04) \\
\text { TNBC subset: } 39.3 \% \text { (with bevacizumab) } \\
\text { versus } 27.9 \% \text { (no bevacizumab) } \\
(P=0.003)\end{array}$ \\
\hline NSABP B-40 & $\begin{array}{l}\text { Bear } \\
\text { et al. (2012) }\end{array}$ & $\begin{array}{l}\text { HER2- negative } \\
\text { breast can- } \\
\text { cer }(n=1206)\end{array}$ & $\begin{array}{l}\text { (Docetaxel vs. Docetaxel/ } \\
\text { Gemcitabine vs. Docetaxel/ } \\
\text { Capecitabine) } \rightarrow \text { AC; sec- } \\
\text { ondary randomisation to } \\
\text { bevacizumab }\end{array}$ & $\begin{array}{l}\text { In-breast pCR: Evaluable patients } \\
34.5 \% \text { (with bevacizumab) versus } \\
28.2 \% \text { (chemotherapy alone) }(P=0.02) \\
\text { HR-negative (TNBC) Subset } \\
51.5 \% \text { (with bevacizumab) versus } \\
47.1 \% \text { (chemotherapy alone) }(P=0.34)\end{array}$ \\
\hline $\begin{array}{l}\text { CALGB } \\
40603\end{array}$ & $\begin{array}{l}\text { Sikov } \\
\text { et al. (2013) }\end{array}$ & $\operatorname{TNBC}(n=443)$ & $\begin{array}{l}2 \times 2 \text { Randomisation: Weekly } \\
\text { Paclitaxel } \rightarrow \text { ddAC } \pm \text { Carboplat- } \\
\text { in } \pm \text { Bevacizumab }\end{array}$ & $\begin{array}{l}\text { In-breast pCR: } 60 \% \text { (with carboplatin) } \\
\text { vs. } 46 \% \text { (no carboplatin) (P=.0018) } \\
59 \% \text { (with bevacizumab) vs. } 48 \% \text { (with- } \\
\text { out bevacizumab) }(P=.0089 \text { ) } \\
\text { pCR (breast+nodes): } 54 \% \text { (with } \\
\text { carboplatin) versus } 41 \% \text { (no carbopla- } \\
\text { tin) ( } P=0.0029) 52 \% \text { (with bevacizumab) } \\
\text { versus } 44 \% \text { (without bevacizumab) } \\
(P=0.0570)\end{array}$ \\
\hline GeparSixto & $\begin{array}{l}\text { Von } \\
\text { Minckwitz } \\
\text { et al. (2014) }\end{array}$ & $\operatorname{TNBC}(n=315)$ & $\begin{array}{l}\text { Weekly Paclitaxel/PLD/beva- } \\
\text { cizumab } \pm \text { Carboplatin }\end{array}$ & $\begin{array}{l}\text { pCR (breast+nodes): } 53.2 \% \text { (carbo- } \\
\text { platin) versus } 36.9 \% \text { (no carbopla- } \\
\text { tin) }(P=0.005)\end{array}$ \\
\hline
\end{tabular}

HR: Hormone receptor, TNBC: Triple-negative breast cancer, EC: Epirubicin/cyclophosphamide, Pcr: Pathologic complete response, NSABP: National Surgical Adjuvant Breast and Bowel Project, AC: Doxorubicin/cyclophosphamide, CALGB: Cancer and leukaemia group B, ddAC: Dose-dense doxorubicin/cyclophosphamide, PLD: Pegylated liposomal doxorubicin

on a Bayesian prediction model. ${ }^{[18]}$ A large phase 3 randomised study is evaluating this combination in TNBC (clinicaltrials.gov NCT02032277).

The first randomised comparison of nab-paclitaxel versus solvent-based ( $\mathrm{sb}$ )-paclitaxel in the neoadjuvant setting was presented recently. Results from the randomised GeparSepto trial demonstrated a superior pCR rate (breast plus nodes) with nab-paclitaxel versus weekly sb-paclitaxel in the context of a standard anthracycline/ taxane neoadjuvant regimen (38\% vs. $29 \% ; P=0.001)$, although the rate of Grade 3/4 peripheral neuropathy was also increased. ${ }^{[19]}$ Notably, the subset of patients with TNBC appeared to derive the greatest benefit from nabpaclitaxel in this study (odds ratio 2.69, pCR rates $48 \%$ vs. $29 \% P<0.001)$. It is likely that, within TNBC, certain molecular subsets (e.g. the mesenchymal or mesenchymal stem cell-like $)^{[20]}$ with high expression of genes encoding for epithelial-mesenchymal transition (e.g. SPARC) could potentially be more sensitive to nab-paclitaxel compared to sb-paclitaxel. Correlative analyses to be conducted in the near future on the pre-operative biopsy samples from our study and studies like the GeparSepto trial may lend some useful insight into this.

Bevacizumab has been evaluated for neoadjuvant breast cancer treatment in randomised trials that included subsets of TNBC patients [Table 4]. Although small increases in pCR rates were observed in the National Surgical Adjuvant Breast and Bowel Project B-40 and GeparQuinto trials with the addition of bevacizumab to chemotherapy, the benefit in the TNBC subset was not consistent [Table 4]. ${ }^{[21,22]}$ Correlative data from the CALGB 40603 study do lend a worthwhile hypothesis 
for a basal-like intrinsic subtype, higher expression of a proliferation signature and lower expression of oestrogen signature as being predictive of increased $\mathrm{pCR}$ rates with bevacizumab. These will require further large-scale validation before being considered for stratification of patients for treatment decisions. ${ }^{[18]}$

In our trial, patients also received an additional eight cycles of bevacizumab after completion of surgery. Results of this phase are not yet mature and will be reported in the future. However, 1 year of adjuvant bevacizumab plus chemotherapy for patients with TNBC in the phase III BEATRICE trial produced no improvement in invasive DFS or OS compared to chemotherapy alone. ${ }^{[23]}$ Similarly, the recently presented ECOG 5103 adjuvant trial in HER2-negative breast cancer did not show a DFS advantage for 6 or 12 months of postoperative bevacizumab added to chemotherapy versus chemotherapy alone. ${ }^{[24]}$ These data together do not support a significant role of bevacizumab in the treatment of earlystage TNBC at this point in time. Correlative biomarkers from these large adjuvant studies might identify potential subgroups of patients likely to derive benefit.

With regard to tolerability, the majority of AEs in our study were Grade 1/2, with a $14 \%$ rate of Grade 3 or 4 events. Despite the high rate of Grade 3/4 neutropenia, the rate of febrile neutropenia was very low, likely due to the frequent use of G-CSF after cycle 1. The rates of neutropenia are consistent with other trials combining both carboplatin and bevacizumab with standard neoadjuvant chemotherapy. Also consistent among the different trials is the observation that the addition of carboplatin with or without bevacizumab interferes with the delivery of all 12 planned weekly doses of the taxane. In our study and in CALGB $40603,{ }^{[17]}$ approximately $60-65 \%$ of the patients received 11-12 planned doses of the taxane when both carboplatin and bevacizumab were also administered. In the GeparSixto trial, the mean relative total dose intensity (RTDI) of all treatments in the TNBC cohort was $80 \%$ without and $71 \%$ with carboplatin $(P<0.0001) .{ }^{[16]}$ The mean RTDI increased from $68 \%$ to $72 \%$ when the dose of carboplatin was reduced from an AUC of 2 to AUC 1.5, accompanied by a lower rate of treatment discontinuation. ${ }^{[16]}$

This study along with the other recent neoadjuvant studies discussed above underscores the heterogeneity of the TNBC population, and not all patients benefit from the addition of platinum agents and other targeted therapies. The additional toxicity and the compromised delivery of the standard backbone drugs need to be kept in mind when advocating for more intensified neoadjuvant regimens for all patients with TNBC. Future studies should focus on evaluating distinct molecular subsets with differing sensitivity to cytotoxic and biologic agents. ${ }^{[20,25]}$ For instance, an analysis of homologous recombination deficiency (HRD) in breast cancer identified one-third of TNBCs $(36 \%)$ that could potentially benefit from DNA damaging drugs like ${ }^{[26,27]}$ the platinum compounds alone or in combination with poly (ADP ribose) polymerase (PARP) inhibitors based on HRD. ${ }^{[26]}$ The PrECOG study 0105 evaluated the combination of carboplatin plus gemcitabine plus iniparib neoadjuvantly in TNBC patients with or without germline BRCA mutations. ${ }^{[27]}$ A higher pCR rate was observed for tumours with a higher HRD score irrespective of germline BRCA status. Subclassification of responders and non-responders into molecular subsets showed the highest responses in the immunomodulatory subset and no responses in the luminal androgen receptor-like subset. Recent data from the GeparSixto trial correlated a higher expression of immunerelated genes and tumour-infiltrating lymphocytes with higher pCR rates. ${ }^{[28]}$ The development of multiple T-cell checkpoint inhibitors might offer an opportunity to further enhance response to neoadjuvant chemotherapy for patients in the near future.

Finally, in a recently published pooled analysis of 12 neoadjuvant breast cancer studies, the prognostic correlation of pCR with event-free survival (EFS) and OS was shown for TNBC and HER2-positive breast cancer treated with trastuzumab. ${ }^{[29]}$ Alhough the individual trial level data failed to show a correlation between the treatment effect on pCR and EFS or OS, the authors concluded that the heterogeneous study populations and the small absolute difference in pCR rates between the treatment and control arms in the majority of these trials were unlikely to be sufficient to impact a change in EFS and OS. More effective therapies in homogeneous subsets of breast cancer that produce larger absolute differences in pCR rates, as reported by our group and other contemporary trials, could be speculated to produce a meaningful treatment effect on EFS and OS when analysed in the future. 


\section{Conclusion}

Our study has demonstrated substantially higher $\mathrm{pCR}$ rates with the combination of nab-paclitaxel plus carboplatin followed by AC, with concurrent bevacizumab, compared with historic rates associated with anthracycline-taxane regimens alone. Correlative data from this study and the other recent studies exploring similar combinations will hopefully allow selection of certain subsets of TNBC patients for whom further investigation of this regimen would be warranted. Longer follow-up of our study and others is needed to establish the impact of these novel regimens on survival outcomes in TNBC.

\section{Acknowledgements and Funding}

We would like to thank all of the patients, physicians and clinical research coordinators who participated in this study and Susan R. Peck for editorial assistance. This study was approved and funded by the National Comprehensive Cancer Network Oncology Research Program from general research support from Celgene Corporation.

\section{Author Disclosures}

Jasgit C. Sachdev has a consultant/advisory role and has received research funding from Celgene Corporation. All other authors declare they have no conflicts of interest.

\section{Conflict of Interest}

The authors declare that they have no conflict of interest.

\section{References}

1. Rouzier R, Perou CM, Symmans WF, et al. Breast cancer molecular subtypes respond differently to preoperative chemotherapy. Clin Cancer Res 2005;11:5678-85.

2. Carey LA, Dees EC, Sawyer L, et al. The triple negative paradox: Primary tumor chemosensitivity of breast cancer subtypes. Clin Cancer Res 2007;13:2329-34.

3. Bear HD, Anderson S, Smith RE, et al. Sequential preoperative or postoperative docetaxel added to preoperative doxorubicin plus cyclophosphamide for operable breast cancer: National surgical adjuvant breast and bowel project protocol B-27. J Clin Oncol 2006;24:2019-27.

4. Wolmark N, Wang J, Mamounas E, et al. Preoperative chemotherapy in patients with operable breast cancer: Nineyear results from national surgical adjuvant breast and bowel project B-18. J Natl Cancer Inst Monogr 2001;30:96-102.

5. von Minckwitz G, Raab G, Caputo A, et al. Doxorubicin with cyclophosphamide followed by docetaxel every 21 days compared with doxorubicin and docetaxel every 14 days as preoperative treatment in operable breast cancer: The GEPARDUO study of the German breast group. J Clin Oncol 2005;23:2676-85.

6. Gradishar WJ, Tjulandin S, Davidson N, et al. Phase III trial of nanoparticle albumin-bound paclitaxel compared with polyethylated castor oil-based paclitaxel in women with breast cancer. J Clin Oncol 2005;23:7794-803.

7. Charafe-Jauffret E, Ginestier C, Monville F, et al. Gene expression profiling of breast cell lines identifies potential new basal markers. Oncogene 2006;25:2273-84.

8. Desai NP, Trieu V, Hwang LY, et al. Improved effectiveness of nanoparticle albumin-bound (nab) paclitaxel versus polysorbate-based docetaxel in multiple xenografts as a function of HER2 and SPARC status. Anticancer Drugs 2008;19:899-909.

9. Turner N, Tutt A, Ashworth A. Hallmarks of "BRCAness" in sporadic cancers. Nat Rev Cancer 2004;4:814-9.

10. Turner NC, Reis-Filho JS, Russell AM, et al. BRCA1 dysfunction in sporadic basal-like breast cancer. Oncogene 2007;26:2126-32.

11. Loesch D, Robert N, Asmar L, et al. Phase II multicenter trial of a weekly paclitaxel and carboplatin regimen in patients with advanced breast cancer. J Clin Oncol 2002;20:3857-64.

12. Perez EA, Hillman DW, Stella PJ, et al. A phase II study of paclitaxel plus carboplatin as first-line chemotherapy for women with metastatic breast carcinoma. Cancer 2000;88:124-31.

13. Stinchcombe TE, Socinski MA, Walko CM, et al. Phase I and pharmacokinetic trial of carboplatin and albuminbound paclitaxel, ABI-007 (Abraxane) on three treatment schedules in patients with solid tumors. Cancer Chemother Pharmacol 2007;60:759-66.

14. Miller K, Wang M, Gralow J, et al. Paclitaxel plus bevacizumab versus paclitaxel alone for metastatic breast cancer. N Engl J Med 2007;357:2666-76.

15. Carboplatin Dosing. US Food and Drug Administration Website. Available from: http://www.fda.gov/AboutFDA/ CentersOffices/Office ofMedicalProductsandTobacco/ CDER/ucm228974.ht m. [Last accessed on 2010 Oct 08; Last cited on 2014 Dec 04].

16. von Minckwitz G, Schneeweiss A, Loibl S, et al. Neoadjuvant carboplatin in patients with triple-negative and HER2-positive early breast cancer (GeparSixto; GBG 66): A randomised phase 2 trial. Lancet Oncol 2014;15:747-56.

17. Sikov WM, Berry DA, Perou CM, et al. Impact of the addition of carboplatin and/or bevacizumab to neoadjuvant once-per-week paclitaxel followed by dosedense doxorubicin and cyclophosphamide on pathologic complete response rates in stage II to III triple-negative breast cancer: CALGB 40603 (Alliance). J Clin Oncol 2015;33:13-21. 
18. Rugo HS, Olopade O, DeMichele A, et al. Veliparib/ carboplatin plus standard neoadjuvant therapy for high-risk breast cancer: First efficacy results from the I-SPY 2 TRIAL. Presented at: The $36^{\text {th }}$ Annual San Antonio Breast Cancer Symposium. San Antonio; 2013.

19. Untch M, Jackisch C, Schneeweiss A, et al. A Randomized Phase III Trial Comparing Neoadjuvant Chemotherapy with Weekly Nanoparticle-Based Paclitaxel with Solvent-Based Paclitaxel Followed by Anthracycline/Cyclophosphamide for Patients with early Breast Cancer (GeparSepto); GBG 69. Presented at: The $37^{\text {th }}$ Annual San Antonio Breast Cancer Symposium. San Antonio; 2014. Abstract S2-07.

20. Lehmann BD, Bauer JA, Chen X, et al. Identification of human triple-negative breast cancer subtypes and preclinical models for selection of targeted therapies. J Clin Invest 2011;121:2750-67.

21. Bear HD, Tang G, Rastogi P, et al. Bevacizumab added to neoadjuvant chemotherapy for breast cancer. N Engl J Med 2012;366:310-20

22. von Minckwitz G, Eidtmann H, Rezai M, et al. Neoadjuvant chemotherapy and bevacizumab for HER2-negative breast cancer. N Engl J Med 2012;366:299-309.

23. Cameron D, Brown J, Dent R, et al. Adjuvant bevacizumabcontaining therapy in triple-negative breast cancer (BEATRICE): Primary results of a randomised, phase 3 trial. Lancet Oncol 2013;14:933-42.
24. Miller K, O'Neill AM, Dang CT, et al. Bevacizumab $(\mathrm{Bv})$ in the adjuvant treatment of HER2-negative breast cancer: Final results from eastern cooperative oncology group E5103. J Clin Oncol 2014;32 Suppl:500.

25. Masuda H, Baggerly KA, Wang Y, et al. Differential response to neoadjuvant chemotherapy among 7 triplenegative breast cancer molecular subtypes. Clin Cancer Res 2013;19:5533-40.

26. Timms KM, Abkevich V, Neff C, et al. Association between BRCA1/2 status and DNA-Based Assays for Homologous Recombination Deficiency in Breast Cancer. Presented at: The $36^{\text {th }}$ Annual San Antonio Breast Cancer Symposium. San Antonio: 2013. Abstract P6-05-10.

27. Telli ML, Jensen KC, Kurian AW, et al. PrECOG 0105: Final efficacy results from a phase II study of gemcitabine $(G)$ and carboplatin (C) plus iniparib (BSI-201) as neoadjuvant therapy for triple-negative (TN) and BRCA1/2 mutationassociated breast cancer. J Clin Oncol 2013;31 Suppl:1003.

28. Denkert C, Von Minckwitz G, Brase JC, et al. Expression of immunologic genes in triple-negative and HER2-positive breast cancer in the neoadjuvant GEPARSIXTO trial: Prediction of response to carboplatin-based chemotherapy. J Clin Oncol 2014;32 Suppl:510.

29. Cortazar P, Zhang L, Untch M, et al. Pathological complete response and long-term clinical benefit in breast cancer: The CTNeoBC pooled analysis. Lancet 2014;384:164-72. 


\section{Supplemental Table and Appendix}

\section{Supplemental Table 1: Serious adverse events occurring during the pre-operative phase}

\begin{tabular}{l|c}
\hline Symptoms & $\boldsymbol{n}(\%)$ \\
\hline Anaemia & $1(4)$ \\
\hline Cardiac troponin T elevation & $1(4)$ \\
\hline Chest pressure & $1(4)$ \\
\hline Dehydration & $2(9)$ \\
\hline Epistaxis & $2(9)$ \\
\hline Failure to thrive & $1(4)$ \\
\hline Fever & $1(4))$ \\
\hline Ischaemic chest pain & $1(4)$ \\
\hline Mucositis & $1(4)$ \\
\hline Nausea & $1(4)$ \\
\hline Neutropenia & $5(22)$ \\
\hline Pharyngitis & $1(4)$ \\
\hline Syncope & $1(4)$ \\
\hline Thrombocytopenia & $2(9)$ \\
\hline Vomiting & $2(9)$ \\
\hline
\end{tabular}

Supplementary Appendix 1: Dosage and Schedule Modifications for Haematologic and Non-Haematologic Toxicities

Carboplatin and/or $n a b$-paclitaxel were delayed and/or reduced for absolute neutrophil counts (ANC) of $<1500 \mu \mathrm{L}$, or platelet counts $<100,000$ lasting $\leq 3$ weeks; withdrawal from the study was required if ANC or platelets had not recovered within 3 weeks. nab-Paclitaxel was delayed and/ or dose reduced for Grade 2/3 peripheral neuropathy, and drug was discontinued for Grade 4 events, Grade 3 events persisting $>7$ days, or for the third episode of Grade 3 neuropathy of 1-7 days duration. Carboplatin and/or nabpaclitaxel were discontinued at the second occurrence of Grade 3/4 hepatic function abnormalities or mucositis, or other Grade 4 non-hematologic adverse events. Midstudy, in compliance with the FDA guidance issued around changes in creatinine methodology and carboplatin dosing, a GFR cap of $125 \mathrm{~mL} / \mathrm{min}$ was implemented for the Calvert formula so that the maximum dose of carboplatin for any patient was not to exceed $900 \mathrm{mg}$.

Doxorubicin and/or cyclophosphamide were delayed and/or reduced for $\mathrm{ANC}<1000 / \mu \mathrm{L}$, platelet counts $<75,000$ lasting $\leq 3$ weeks, or for febrile neutropenia; withdrawal from the study was required if $\mathrm{ANC}$ or platelets had not recovered within 3 weeks, and treatment was discontinued at the third episode of febrile neutropenia. Doxorubicin and/or cyclophosphamide were discontinued for the second occurrence of Grade 3/4 vomiting or mucositis, Grade 4 hepatic function abnormalities or Grade 2/3 abnormalities persisting $>3$ weeks, or for Grade 3/4 hand-foot syndrome requiring greater than a 3 weeks delay.

No dose reductions of bevacizumab were allowed, and treatment was held if the chemotherapy component was delayed. Bevacizumab was held for a left ventricular ejection fraction (LVEF) drop $\geq 16 \%$ points below baseline or $\geq 6 \%$ points below lower limit of normal, and permanently discontinued if LVEF did not meet continuation criteria at the designated follow-up assessment. Grade 3 congestive heart failure (CHF) required discontinuation of bevacizumab at any cycle, and $\mathrm{AC}$ was prohibited; all study therapies were discontinued for Grade $4 \mathrm{CHF}$ or for Grade 3/4 cardiac ischaemia/infarction. Bevacizumab was discontinued for Grade 2-4 cardiac conduction abnormalities, Grade 3/4 supraventricular arrhythmia, or Grade 2-4 ventricular arrhythmia occurring during cycles 1-4; bevacizumab and $\mathrm{AC}$ were discontinued if these events occurred during cycles 5-8. Bevacizumab was also discontinued and patients withdrawn from study treatment for any grade arterial thrombolic events, Grade 4 proteinuria, Grade 4 or uncontrolled Grade 3 hypertension, gastrointestinal perforation, fistula, reversible posterior leucoencephalopathy, wound dehiscence, or any other Grade 4 adverse events attributable to bevacizumab. If bevacizumab was discontinued during the pre-operative phase, no post-operative bevacizumab was allowed.

\section{Supplementary Appendix 2: RECIST Version 1.0 Criteria for Clinical Response Assessment ${ }^{1}$}

\section{Definition of target and non-target lesions at baseline}

during the baseline assessment, all lesions detected in the breast and axilla are classified as either target lesions or non-target lesions before the start of protocol treatment. 
Target lesions include:

- $\quad$ Breast tumours $\geq 2.0 \mathrm{~cm}$ on baseline physical examination

- Axillary nodes $\geq 2.0 \mathrm{~cm}$ on baseline physical examination.

Non-target lesions include:

- Breast tumours $<2.0 \mathrm{~cm}$ on baseline physical examination

- Axillary nodes $<2.0 \mathrm{~cm}$ on baseline physical examination.

\section{Clinical Measurement}

For the target lesion(s) in the breast and axilla, the longest unidimensional measurement (longest diameter, LD) was recorded. The clinical measurement for this assessment is the sum of the LD measurements of all target lesions.

\section{Criteria for Evaluation of Clinical Response}

- Clinical complete response

Disappearance of all target and non-target lesions identified at baseline, with no evidence of disease progression.

\section{- Clinical partial response}

At least a $30 \%$ decrease in the sum of the LD of target lesions (taking as reference the baseline sum of the
LD). No definite progression of non-target lesions. No evidence of new lesions.

\section{- Clinical stable disease}

Neither sufficient shrinkage to qualify for response nor sufficient increase to qualify for progressive disease.

\section{- Progressive disease}

At least a $20 \%$ increase in the sum of the LD of the target lesions (taking as reference the smallest sum of the LD recorded).

\begin{tabular}{l|l|l|l}
\hline $\begin{array}{l}\text { Target } \\
\text { lesions }\end{array}$ & $\begin{array}{l}\text { Non-target } \\
\text { lesions }\end{array}$ & $\begin{array}{l}\text { New } \\
\text { lesions }\end{array}$ & $\begin{array}{l}\text { Overall } \\
\text { response }\end{array}$ \\
\hline CR & CR & No & CR \\
\hline CR & $\begin{array}{l}\text { Incomplete } \\
\text { response/SD }\end{array}$ & No & PR \\
\hline PR & Non-PD & No & PR \\
\hline SD & Non-PD & No & SD \\
\hline PD & Any & Yes or No & PD \\
\hline Any & PD & Yes or No & PD \\
\hline Any & Any & Yes & PD \\
\hline
\end{tabular}

${ }^{1}$ Therasse P, Arbuck SG, Eisenhauer EA, et al. New guidelines to evaluate the response to treatment in solid tumors. European Organization for Research and Treatment of Cancer, National Cancer Institute of the United States, National Cancer Institute of Canada. J Natl Cancer Inst 2000;92(3):205-16. 